\title{
The microwave assisted extraction sway on the features of antioxidant compounds and gelling biopolymers from Mastocarpus stellatus
}

\author{
E. Ponthier ${ }^{\mathrm{a}, \mathrm{b}}$, H. Domínguez ${ }^{\mathrm{a}}$, M.D. Torres ${ }^{\mathrm{a}, *}$ \\ ${ }^{a}$ Department of Chemical Engineering, University of Vigo (Campus Ourense), Polytechnic Building, As Lagoas, 32004 Ourense, Spain \\ ${ }^{\mathrm{b}}$ IMT Mines Albi, Allée des Sciences, 81000 Albi, France
}

Keywords:

Algae

Antioxidant

Hybrid carrageenan

Hydrogels

MAE

Rheology

\begin{abstract}
A B S T R A C T
Microwave assisted water extraction of hybrid carrageenan and antioxidant compounds from Mastocarpus stellatus red alga was first proposed to recover biopolymers with specific rheological properties, saving time, avoiding chemicals and enhancing extraction yields when compared with conventional treatments. The hybrid carrageenans, precipitated from the liquid fractions recovered after microwave assisted water extraction were analyzed by Fourier transform infrared attenuated total reflectance, high-performance size-exclusion chromatography and rheology. The corresponding soluble extracts were also characterized by total phenolic content, antioxidant capacity, proteins, sulfate and carbohydrate content. The highest phenolic, antioxidant capacity and sulfate content were observed at $190{ }^{\circ} \mathrm{C}$, without notable effect of heating time between 3 and 6 min. In contrast, a clear impact of both microwave heating temperature and time on the molecular weight distribution of hybrid carrageenans as well as on the viscoelastic behavior of formulated hydrogels was identified, being the strongest hydrogels achieved at $170{ }^{\circ} \mathrm{C}$ for $6 \mathrm{~min}$. It should be highlighted that all proposed hydrogels exhibited stable mechanical properties in the absence of syneresis for a month of cold storage, except those made with biopolymers obtained with the mildest extraction conditions $\left(3 \mathrm{~min}\right.$ at $\left.70{ }^{\circ} \mathrm{C}\right)$.
\end{abstract}

\section{Introduction}

In the last decade, there has been a growing interest in the macroalgae because they are rich sources of unique bioactive and biopolymerbased compounds with great potential for the food and non-food sector $[1,2]$. Macroalgae are generally classified in the following three groups, Chlorophyta (green algae), Phaeophyta (brown algae) and Rhodophyta (red algae) [3,4]. Namely, the Rhodophyta are rich in bioactive compounds such as proteins, carotenoids, phenolics or vitamins [5] as well as an important source of gelling biopolymers like carrageenan or agar, which represents about $20 \%$ on dry basis [6].

Carragenophyte seaweeds produce different carrageenan types like kappa-, iota- or lamba- and are widely distributed by the western and eastern coasts of the North to mid-Atlantic [6]. These polysaccharides are sulfated galactans which are produced mainly by Gigartinales species as their main cell-wall material [7]. Carrageenans can have gelling, thickening and emulsifying properties [8], representing a huge growing market of several millions dollars $[9,10]$. This relevant fact can be explained taking into account that carrageenan is a natural polymer and the world is more and more concerned about sustainability issues [11]. A number of factors can affect the chemical structure of the carrageenan and thus the gel properties such as alga culture conditions, season when collected, algae health or disease state, maturity degree, post-harvest storage or processing conditions. The extraction method of these biopolymers and the involved conditions with parameters such as temperature, $\mathrm{pH}$ or time can also dramatically impact the biopolymer properties and consequently the mechanical features of the gel [12].

Model red seaweeds as Mastocarpus stellatus, which is an important biomass on the Atlantic coast of Spain and Portugal, can be a suitable alternative for the carrageenan production [11]. This seaweed is considered as a model because it shows a wide geographical distribution with limited variability in the chemical structure of extracted kappaiota carrageenan attributable to the collection site conditions [7]. Moreover, it is a promising candidate for integrated multitrophic aquaculture and thus a future sustainable resource for the production of hybrid carrageenan in Europe [13,14]. Namely, this seaweed produce kappa/iota- hybrid carrageenans, which are natural polyelectrolyte copolymers made of blocks of kappa- (sequences of alternating 3-linked $\beta$-D-galactopyranose with a sulphate group on the fourth carbon of the sugar ring and 4-linked $\alpha$-D-anhydrogalactopyranose) and blocks of iota- (sequences of alternating 3-linked $\beta$-D-galactopyranose with a sulphate group on the fourth carbon of the sugar ring and 4-linked $\alpha$-D-

\footnotetext{
* Corresponding author.

E-mail address: matorres@uvigo.es (M.D. Torres).
} 


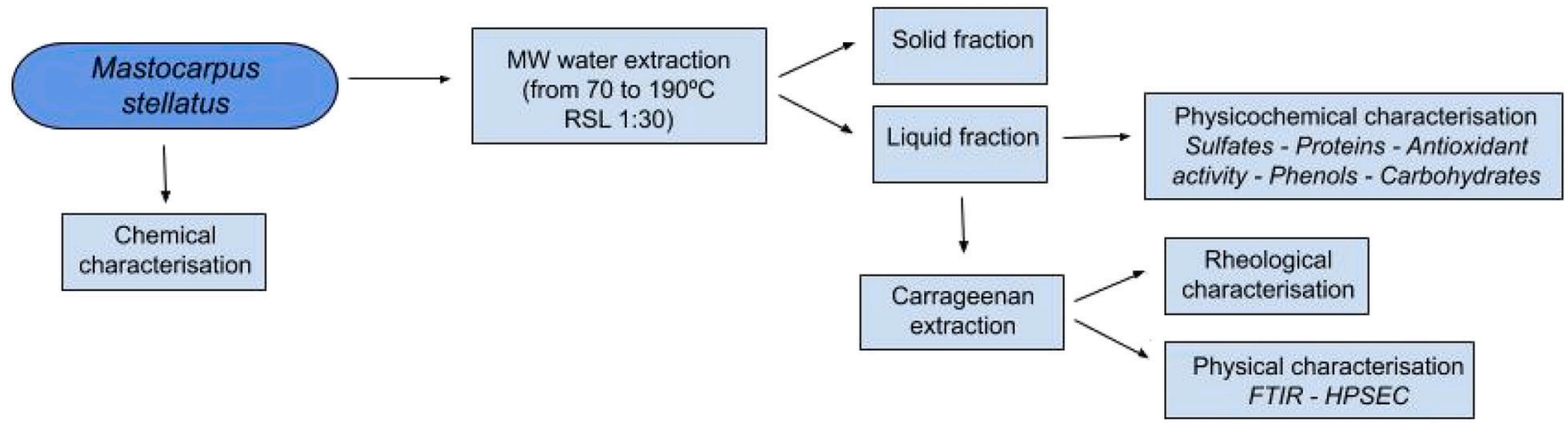

Fig. 1. General scheme of Mastocarpus stellatus treatment by microwave assisted extraction. MW: Microwave, RSL: Solid liquid ratio, FTIR: Fourier transform infrared attenuated total reflectance, HPSEC: high-performance size-exclusion chromatography.

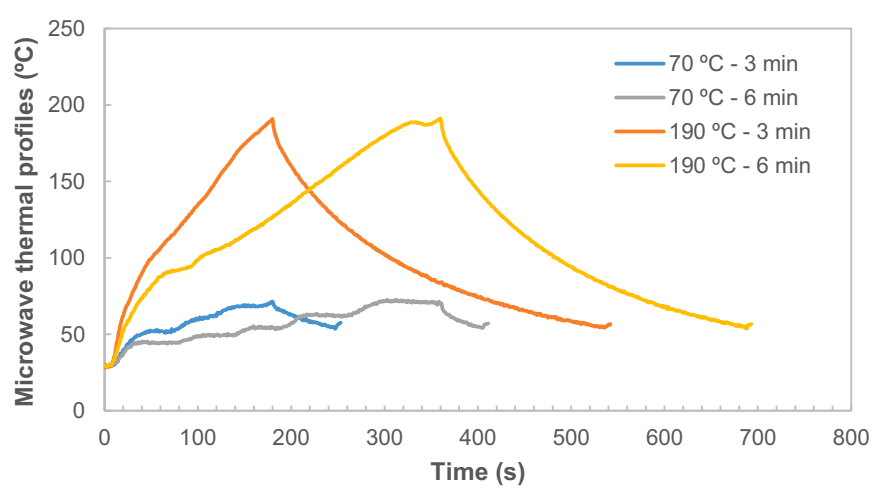

Fig. 2. Thermal profiles for microwave assisted extraction of tested systems at different heating temperatures $\left(70-190^{\circ} \mathrm{C}\right.$ ) and times $\left(\mathrm{t}_{\mathrm{MW}}: 3,6 \mathrm{~min}\right)$. Note here that standard deviations were lower than $1 \%$ in all cases $(n=3)$.

anhydrogalactopyranose bearing a sulphate group on the second carbon of the anhydro ring). These biopolymers commonly show enhanced mechanical properties when compared with individual kappa or iota carrageenan, exhibiting intermediate gelling properties [15,16]. Namely, kappa carrageenan can provide hard, strong or brittle gels, whereas iota carrageenan commonly forms soft and weak gels. Thus, the hybridization allows the formation of a strong elastic gel [15]. The kappa/iota hybrid carrageenan gels can have many applications in different industries [16]. It could be used in the dairy industry for cakes, in cosmetic for creams or lotions, in the pharmaceutical industry for semi-synthetic antibiotic production, in chemicals for paints or shoe polish, in experimental medicine for the testing of anti-inflammatory drugs or in biotechnology to immobilize cells/enzymes, among many others $[17,18,19]$.

Microwave assisted extraction (MAE) is a relatively new, green and scalable process for the recovery of high valuable natural compounds $[10,20,21,22]$, that could also be an attractive alternative for the recovery of hybrid carrageenans or antioxidants from macroalgae [23,24]. MAE allows a fast and uniform extraction, compact equipment, fast start-up, short time, less solvent and energy, which can be explained by the effect of microwaves on molecules by ionic conduction and dipole rotation [25,26]. Some authors [27] studied the microwaveassisted alkaline modification of red seaweed galactans to enhance their gelation behavior, accelerating the reaction several times with respect to that performed with conventional heating $[18,23]$. Later works indicated the integrity of the polysaccharides treated by MAE was not affected by this procedure [28]. However, a thermal degradation of some components can occur [29,30,31].

In this context, the main objective of this novel work is to study the impact of microwave assisted extraction on the properties of the hybrid carrageenans and antioxidant compounds recovered from Mastocarpus stellatus for the integral valorization of this model red seaweed. For this purpose, the composition of the soluble extracts and the physical characterization of the gelling biopolymers obtained at different microwave processing conditions, as well as the rheological characterization of the corresponding gels were analyzed.

\section{Materials and methods}

\subsection{Raw materials}

Dehydrated Mastocarpus stellatus algae of ecological production (moisture content of $11.54 \pm 0.25 \%$, w.b. and ash content of $17.83 \pm 0.19 \%$ ) were provided by Porto Muíños company (A Coruña, Spain). Algae were stored in closed dark plastic bags at room temperature before and after being milled until to be processed. Fundamental chemical properties of the raw material were reported in a parallel work [24].

\subsection{Microwave assisted extraction}

Milled algae (average particle size $<200 \mu \mathrm{m}$ ) were processed by Microwave Assisted Extraction (MAE) using a Microwave reactor Monowave 450 with autosampler Mas 24 (Anton Paar, Austria) for the recovery of high valuable compounds. Particularly, dried milled algae and distilled water were added in the microwave vials at a solid liquid ratio of 1:30 (w:w). Preliminary trials were performed to choose the operation conditions taking into account the outcomes achieved in previous works with seaweeds [32]. The first set of samples were heated for a microwave time $\left(\mathrm{t}_{\mathrm{MAE}}\right)$ of $3 \mathrm{~min}$ at a wide range of temperatures: $70,90,130,150,170,190{ }^{\circ} \mathrm{C}$ and the second set of samples were heated for $t_{\mathrm{MAE}}$ of $6 \mathrm{~min}$ at the same temperatures. Then, both were cooled until $55^{\circ} \mathrm{C}$. Subsequently, the liquid fraction was separated from the solid one by vacuum filtration. The samples were kept in the freezer until further use.

One volume of the liquid fraction obtained by MAE was precipitated with one volume of ethanol ( $96 \%$, Sigma-Aldrich, USA). The precipitate was separated by filtration if necessary. Then, the recovered biopolymer was dried in an oven at $40{ }^{\circ} \mathrm{C}$. The dried carrageenan was weighed to obtain the yield ( $\mathrm{g}$ hybrid carrageenan/ $\mathrm{g}$ dried alga powder) [12].

\subsection{Composition analysis of the soluble extracts}

\subsubsection{Total phenolic compounds}

Total phenolic content of the soluble extracts obtained by MAE was determined by the Folin-Ciocalteau method [33]. The results were given as grams of Gallic Acid Equivalents (GAE). This is a spectrophotometric method in which it was necessary to mix $0.25 \mathrm{~mL}$ of soluble extracts or gallic acid (CAS no. 149-91-7, Sigma-Aldrich, USA) used as reference, $1.875 \mathrm{~mL}$ of distilled water, $0.175 \mathrm{~mL}$ of Folin reagent (CAS no. 7647-01-0, Panreac Química, Spain): water (1:1, v/v) 

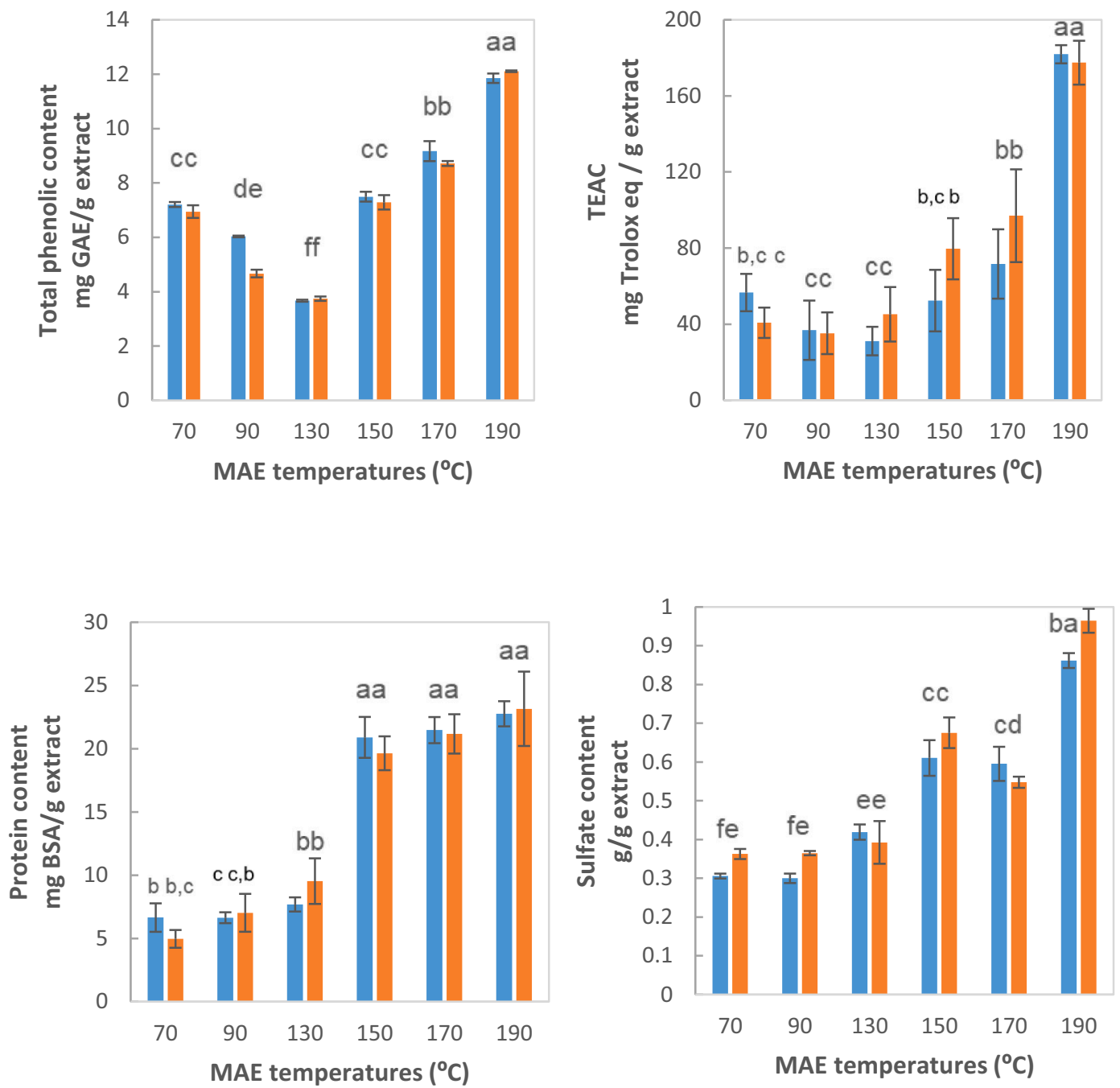

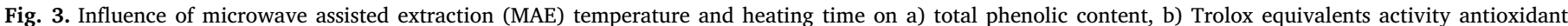

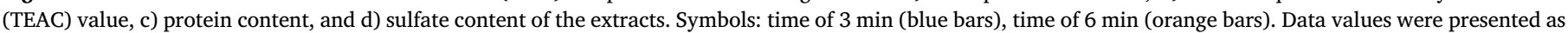

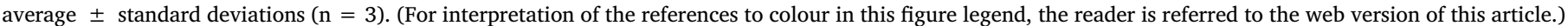

Table 1

Carbohydrate content for soluble extracts recovered from microwave assisted extraction (MAE) at different microwave heating temperatures $\left(70-190{ }^{\circ} \mathrm{C}\right)$ and times (3 and $6 \mathrm{~min}$ ).

\begin{tabular}{|c|c|c|c|c|c|c|c|}
\hline & Composition & $70^{\circ} \mathrm{C}$ & $90{ }^{\circ} \mathrm{C}$ & $130{ }^{\circ} \mathrm{C}$ & $150{ }^{\circ} \mathrm{C}$ & $170{ }^{\circ} \mathrm{C}$ & $190{ }^{\circ} \mathrm{C}$ \\
\hline \multirow[t]{5}{*}{ Time, $3 \mathrm{~min}$} & Glucose (\%) & $4.1 \pm 0.1^{\mathrm{e}}$ & $4.9 \pm 0.3^{\mathrm{d}}$ & $6.2 \pm 0.2^{c}$ & $6.8 \pm 0.1^{\mathrm{b}}$ & $7.3 \pm 0.1^{\mathrm{a}}$ & $5.8 \pm 0.1^{\mathrm{c}}$ \\
\hline & Xylose (\%) & $1.5 \pm 0.1^{\mathrm{d}}$ & $2.0 \pm 0.1^{\mathrm{c}}$ & $2.6 \pm 0.2^{\mathrm{b}}$ & $2.8 \pm 0.1^{\mathrm{b}}$ & $3.2 \pm 0.1^{\mathrm{a}}$ & $1.7 \pm 0.4^{\mathrm{c}, \mathrm{d}}$ \\
\hline & Galactose (\%) & $19.7 \pm 0.4^{\mathrm{e}}$ & $22.4 \pm 0.8^{\mathrm{d}}$ & $29.2 \pm 1.1^{\mathrm{c}}$ & $30.6 \pm 0.6^{\mathrm{b}}$ & $32.8 \pm 0.5^{\mathrm{a}}$ & $23.9 \pm 1.2^{c}$ \\
\hline & Acetic acid (\%) & $31.6 \pm 0.5^{\mathrm{a}}$ & $30.9 \pm 0.9^{\mathrm{a}}$ & $29.1 \pm 0.2^{\mathrm{b}}$ & $20.1 \pm 0.8^{\mathrm{c}}$ & $15.5 \pm 0.6^{\mathrm{d}}$ & $13.8 \pm 0.5^{\mathrm{e}}$ \\
\hline & Formic acid (\%) & $3.9 \pm 0.2^{\mathrm{d}}$ & $4.1 \pm 0.1^{\mathrm{d}}$ & $4.6 \pm 0.2^{c}$ & $5.5 \pm 0.3^{b}$ & $6.0 \pm 0.2^{\mathrm{a}}$ & $6.1 \pm 0.1^{\mathrm{a}}$ \\
\hline \multirow[t]{5}{*}{ Time, $6 \mathrm{~min}$} & Glucose (\%) & $4.5 \pm 0.5^{\mathrm{e}}$ & $5.1 \pm 0.4^{\mathrm{d}}$ & $6.0 \pm 0.4^{c}$ & $6.9 \pm 0.2^{\mathrm{b}}$ & $7.5 \pm 0.2^{\mathrm{a}}$ & $5.9 \pm 0.3^{\mathrm{c}}$ \\
\hline & Xylose (\%) & $1.7 \pm 0.3^{\mathrm{d}}$ & $2.1 \pm 0.1^{\mathrm{c}}$ & $2.8 \pm 0.3^{\mathrm{b}}$ & $2.9 \pm 0.1^{\mathrm{b}}$ & $3.4 \pm 0.2^{\mathrm{a}}$ & $1.9 \pm 0.2^{\mathrm{c}, \mathrm{d}}$ \\
\hline & Galactose (\%) & $19.9 \pm 0.3^{\mathrm{e}}$ & $22.0 \pm 0.5^{\mathrm{d}}$ & $29.5 \pm 0.9^{c}$ & $31.5 \pm 0.5^{\mathrm{b}}$ & $33.3 \pm 0.7^{\mathrm{a}}$ & $22.5 \pm 1.5^{\mathrm{c}}$ \\
\hline & Acetic acid (\%) & $31.9 \pm 0.3^{\mathrm{a}}$ & $31.4 \pm 0.5^{\mathrm{a}}$ & $29.6 \pm 0.4^{\mathrm{b}}$ & $20.9 \pm 0.4^{\mathrm{c}}$ & $16.0 \pm 0.2^{\mathrm{d}}$ & $14.1 \pm 1.0^{\mathrm{e}}$ \\
\hline & Formic acid (\%) & $3.5 \pm 0.1^{\mathrm{e}}$ & $4.3 \pm 0.2^{\mathrm{d}}$ & $4.9 \pm 0.4^{c}$ & $5.7 \pm 0.3^{\mathrm{b}}$ & $6.2 \pm 0.3^{\mathrm{a}}$ & $6.7 \pm 0.6^{\mathrm{a}}$ \\
\hline
\end{tabular}

Data values are presented as average \pm standard deviations $(n=3)$. Data values in a raw with different superscript letters are significantly different at the $p \leq 0.05$ level.

and $0.25 \mathrm{~mL}$ of $10 \%$ sodium carbonate solution (CAS no. 497-19-8, Sigma-Aldrich, USA). After leaving the test tubes for $60 \mathrm{~min}$ without light, the absorbance was measured at $765 \mathrm{~nm}$.

\subsubsection{Antioxidant capacity}

Antioxidant characteristics of the soluble extracts were obtained by the ABTS (2, 2'-azinobis (3-ethylbenzothiazoline-6-sulfonic acid)) radical scavenging method [34]. The used unit was Trolox Equivalents Activity Antioxidant (TEAC). This is a spectrophotometric method in which it was necessary to add $1 \mathrm{~mL}$ of diluted ABTS (CAS no. 30931-67-0, Sigma-Aldrich, USA) (until the absorbance was 0.7-0.72) to $10 \mu \mathrm{L}$ of soluble extracts or Trolox (6-hydroxy-2,5,7,8-tetramethylchroman-2-carboxylic acid) (CAS no. 53188-07-1, Sigma-Aldrich, USA). The test tubes had to be in bath at $30^{\circ} \mathrm{C}$. Six minutes after 


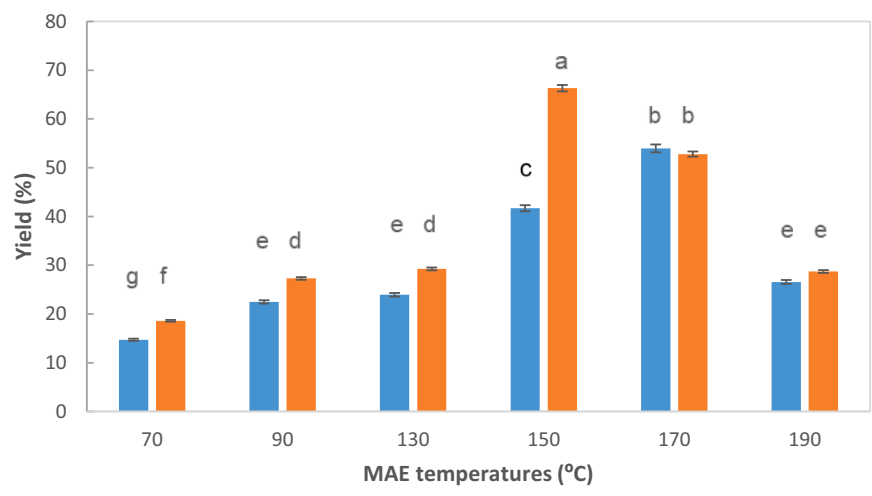

Fig. 4. Influence of microwave assisted extraction (MAE) temperature and heating time on the yield of extracted carrageenan. Symbols: time of $3 \mathrm{~min}$ (blue bars), time of $6 \mathrm{~min}$ (orange bars). Data values were presented as average \pm standard deviations $(n=3)$. (For interpretation of the references to colour in this figure legend, the reader is referred to the web version of this article.)

the addition of diluted ABTS reagent, the absorbance was measured at $734 \mathrm{~nm}$.

\subsubsection{Protein content}

Protein content of the soluble extracts was obtained by the Bradford method [35]. This is a spectrophotometric method which consists in the addition of $790 \mu \mathrm{L}$ of distilled water and $200 \mu \mathrm{L}$ of Bradford reagent (CAS 6104-58-1, Sigma-Aldrich, USA) to $10 \mu \mathrm{L}$ of soluble extracts or Bovine Serum Albumin (BSA) (CAS no. 9048-46-8, Sigma-Aldrich, USA). After an incubation of $5 \mathrm{~min}$ at the room temperature, the absorbance was measured at $595 \mathrm{~nm}$.

\subsubsection{Sulfate groups}

Free sulfate content of the soluble extracts was determined by gelatin-barium chloride method [36]. This is a spectrophotometric method which consists in mixing $0.2 \mathrm{~mL}$ of soluble extracts, $3.8 \mathrm{~mL}$ of $4 \%$ trichloroacetic acid (TCA) (CAS no. 76-03-9, Sigma-Aldrich, USA) and $1 \mathrm{~mL}$ of gelatin - barium chloride reagent. This reagent was prepared by adding $0.5 \mathrm{~g}$ of gelatin powder (CAS no. 9000-70-8, SigmaAldrich, USA) in $100 \mathrm{~mL}$ of hot water $\left(60-70{ }^{\circ} \mathrm{C}\right)$ and let at $4{ }^{\circ} \mathrm{C}$ for at least $6 \mathrm{~h}$, before adding $0.5 \mathrm{~g}$ of $\mathrm{BaCl}_{2}$ (CAS no. 10361-37-2, Sigma Aldrich, USA). After leaving the test tubes for $15 \mathrm{~min}$ at room temperature, the absorbance was measured at $500 \mathrm{~nm}$.

\subsubsection{Monosaccharide analysis}

Liquid samples obtained by MAE were filtered through $0.45 \mu \mathrm{m}$ membranes, neutralized with barium carbonate (CAS no. 513-77-9, Thermo Fisher Scientific, Belgium) before HPLC analysis of carbohydrate compounds. These measurements were conducted on a 1100 series Hewlett-Packard chromatograph (IR detector) operating with a $300 \times 7.8 \mathrm{~mm}$ CARBOsep CHO 682 column (Transgenomic, Glasgow, U.K.) at $80{ }^{\circ} \mathrm{C}$ using Milli Q water as mobile phase $(0.4 \mathrm{~mL} / \mathrm{min})$. Other carbohydrate components were determined by HPLC using $300 \times 7.8 \mathrm{~mm}$ Aminex HPX87H column (BioRad, Hercules, CA) operating at $60{ }^{\circ} \mathrm{C}$ with $0.003 \mathrm{M} \mathrm{H}_{2} \mathrm{SO}_{4}$ (CAS no. 7664-93-9, SigmaAldrich, USA) at $0.6 \mathrm{~mL} / \mathrm{min}$ as mobile phase. The content of oligosaccharides was determined after quantitative posthydrolysis (8\% sulfuric acid at $121{ }^{\circ} \mathrm{C}, 20 \mathrm{~min}$ ). Glucose, xylose, and galactose (Sigma Aldrich, Missouri, USA) were used as standards.

\subsection{Physical characterization of the extracted biopolymer}

\subsubsection{Fourier transform infrared attenuated Total reflectance}

The carrageenan fractions were determined by Fourier Transform Infrared Attenuated Total Reflectance (FTIR-ATR). The measurements were conducted on a Nicolet 6700 spectrometer from 500 to $1500 \mathrm{~cm}^{-1}$ at room temperature for the qualitative characterization of the extracted carrageenan, as detailed elsewhere [37].

\subsubsection{High-performance size-exclusion chromatography}

The molar mass distribution of extracted carrageenan was analyzed by high-performance size-exclusion chromatography (HPSEC) using two $300 \times 7.8 \mathrm{~mm}$ TSKGel G3000PWXL and G2500PWXL columns in series (Tosoh Bioscience, Stuttgart, Germany), a $40 \times 6 \mathrm{~mm}$ PWXguard column at $70{ }^{\circ} \mathrm{C}$ with a refractive index detector. Milli $\mathrm{Q}$ water $(0.4 \mathrm{~mL} / \mathrm{min}$ ) was used as a mobile phase. Dextrans (Fluka Chemie AG, Buchs, Switzerland) with molar masses between 1000 and 80,000 g/ mol were used as standards.

\subsection{Rheology of the developed hydrogels}

Aqueous hybrid carrageenan solutions were made at $1.0 \mathrm{w} / \mathrm{w}(0.5 \%$ at the highest yields) and a fixed ionic strength $(0.1 \mathrm{~mol} / \mathrm{L}$ potassium chloride (CAS no. 7447-40-7, Sigma-Aldrich, USA). The used conditions were chosen based on the results previously reported for this alga using conventional extraction procedures [12]. Note here that the potassium chloride solutions were prepared by dissolving potassium chloride powder in distilled water. Hybrid carrageenan solutions were prepared by dissolving biopolymers at $70-80{ }^{\circ} \mathrm{C}$ under strong stirring until the complete dissolution of carrageenan. Then, the solutions remained in the fridge at $5{ }^{\circ} \mathrm{C}$ for at least $24 \mathrm{~h}$ to allow the full maturation of the gels.

The rheological behavior of above prepared hydrogels was determined on a stress-controlled rheometer (MCR 302, Anton Paar, Graz, Austria) using parallel plates (25 mm diameter and $1 \mathrm{~mm}$ gap). To prevent evaporation, the samples were covered with paraffin oil. First, the samples were kept during $5 \mathrm{~min}$ at $25{ }^{\circ} \mathrm{C}$ to allow temperature equilibration. Then, frequency sweep tests were conducted from 0.1 to $10 \mathrm{~Hz}$, at $10 \mathrm{~Pa}$ and at $25{ }^{\circ} \mathrm{C}$.

\subsection{Statistical analysis}

All measurements were performed at least in triplicate. One-factor analysis of variance was employed to the statistical analysis of the experimental data using PASW Statistics v.22 software (IBM SPSS Statistics, New York, USA). A Scheffé test was carried out to distinguish means with a $95 \%$ of confidence $(p<0.05)$.

\section{Results and discussion}

\subsection{Microwave assisted processing}

The influence of the heating time and temperature during the microwave assisted water extraction of Mastocarpus stellatus was studied following the scheme presented in Fig. 1. After extraction, the solid phase was discarded, and the extract was analyzed for carrageenan and other high valuable compounds. Fig. 2 shows the heating and cooling profiles during water extraction in the microwave assisted process. Note here that the required times are significantly shorter than in a conventionally heated equipment as found in an ongoing work for Mastocarpus stellatus and other marine biomass [38]. Fast microwave treatments with satisfactory results were also previously reported for the alkaline modification of red seaweed galactans using a sharp domestic microwave [27]. It should be noteworthy that microwave extraction times of 3-6 min can provide thermal profiles comparable to those attained in conventionally heated equipment.

\subsection{Composition of microwave-treated soluble extracts}

The impact of different microwave-assisted treatments on the antioxidant features of some sources of marine biomass has been reported 
a)

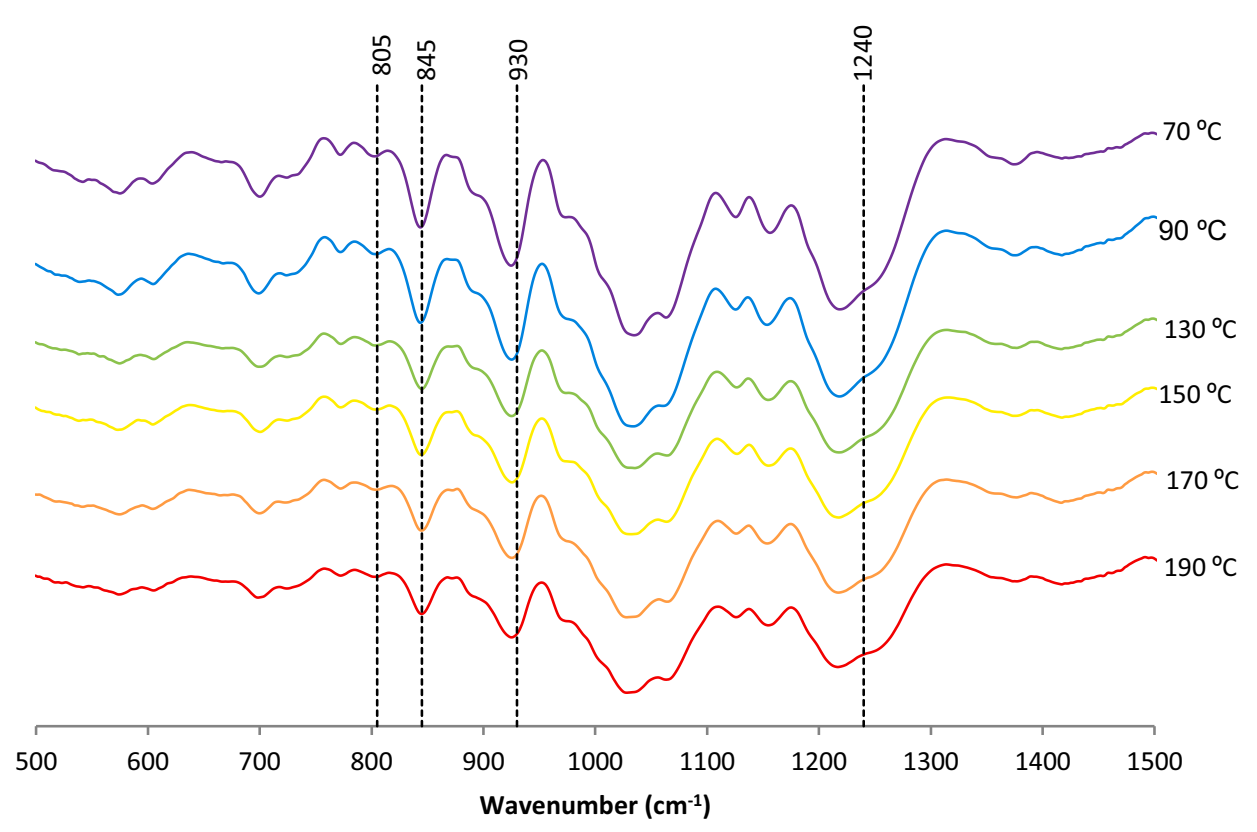

b)

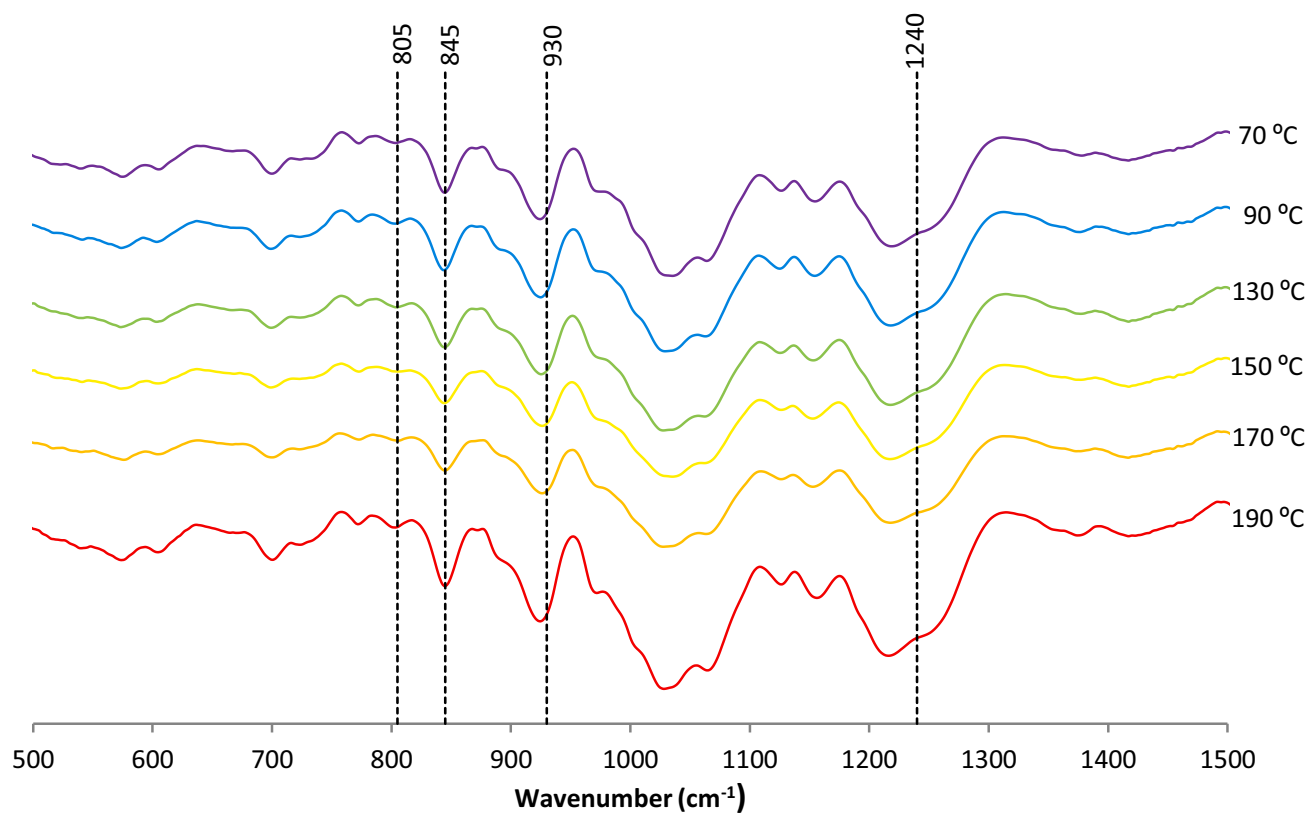

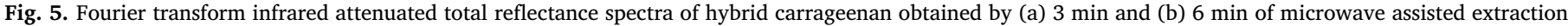
(MAE) heating time. Note here that standard deviations were lower than $1 \%$ in all cases $(n=3)$.

[27]. This eco-friendly treatment not only can accelerate the extraction process, but also promote the recovery of fractions rich in phenolic or sulfate compounds selecting the adequate processing conditions [25,28,39]. Fig. 3 shows that there is no influence of the heating time between 3 and 6 min at different temperatures on the extract composition. The highest phenolic and sulfate content were observed at $190{ }^{\circ} \mathrm{C}$, but the protein content was similar between 150 and $190{ }^{\circ} \mathrm{C}$. The magnitudes of above components were consistent with those previously reported for carrageenophyte red seaweeds using MAE-assisted treatments [28] or conventional alkaline/acid treatments [40,41,42]. A dramatic increase in the ABTS radical scavenging capacity was observed at $190{ }^{\circ} \mathrm{C}$, more marked than the rise in the phenolic content. Probably this activity was due not only to the phenolic content, but also to other components. Similar behaviors highlighting a high increase in yields using optimized microwave aqueous extraction conditions (algae: solvent ratio $1: 30,160{ }^{\circ} \mathrm{C}, 3 \mathrm{~min}$ ) were previously reported for other marine biomass [25]. Higher total phenolic content and antioxidant activity values using this green technique when compared with conventional liquid-solid extractions was also reported in a comprehensive recent review for different macroalgae [39]. Higher bioactive 
a)

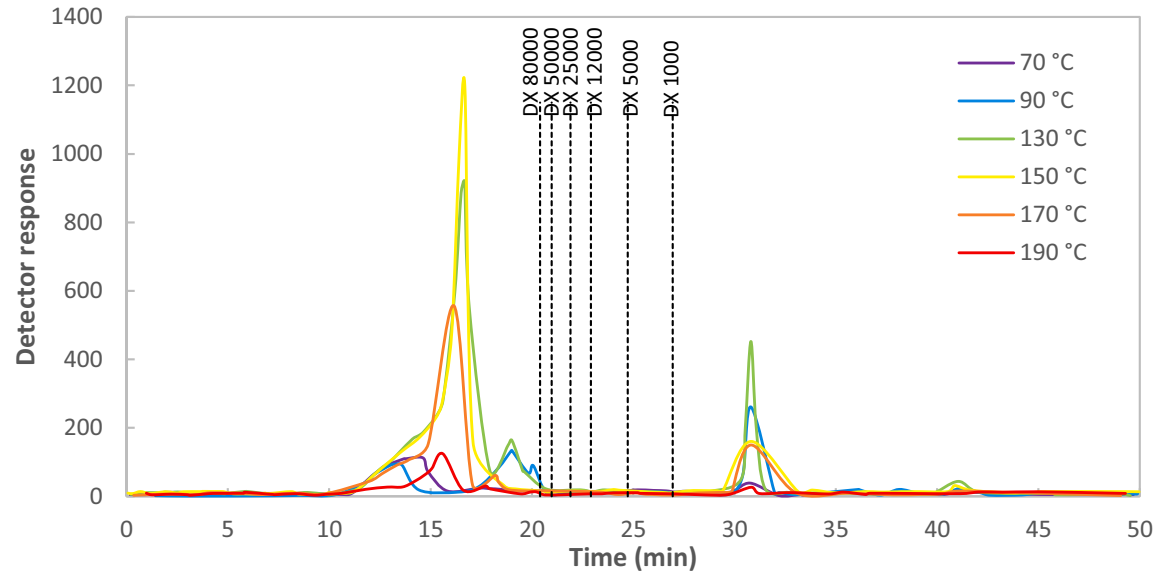

b)

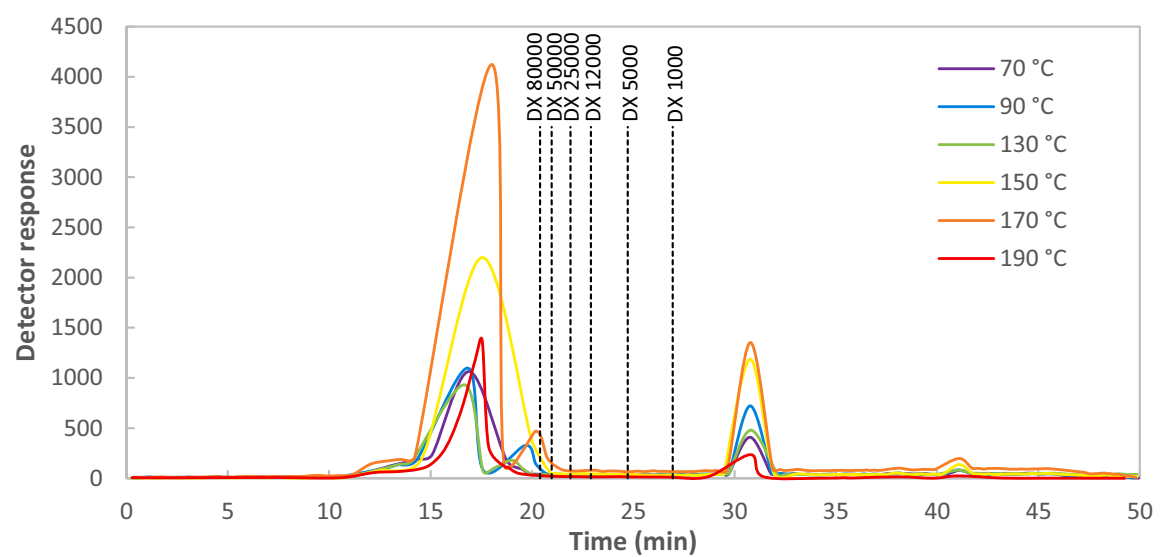

Fig. 6. High-performance size-exclusion chromatography elution profiles of hybrid carrageenan obtained by (a) 3 min and (b) 6 min of microwave assisted extraction (MAE) heating time. Note here that standard deviations were lower than $1 \%$ in all cases $(n=3)$.
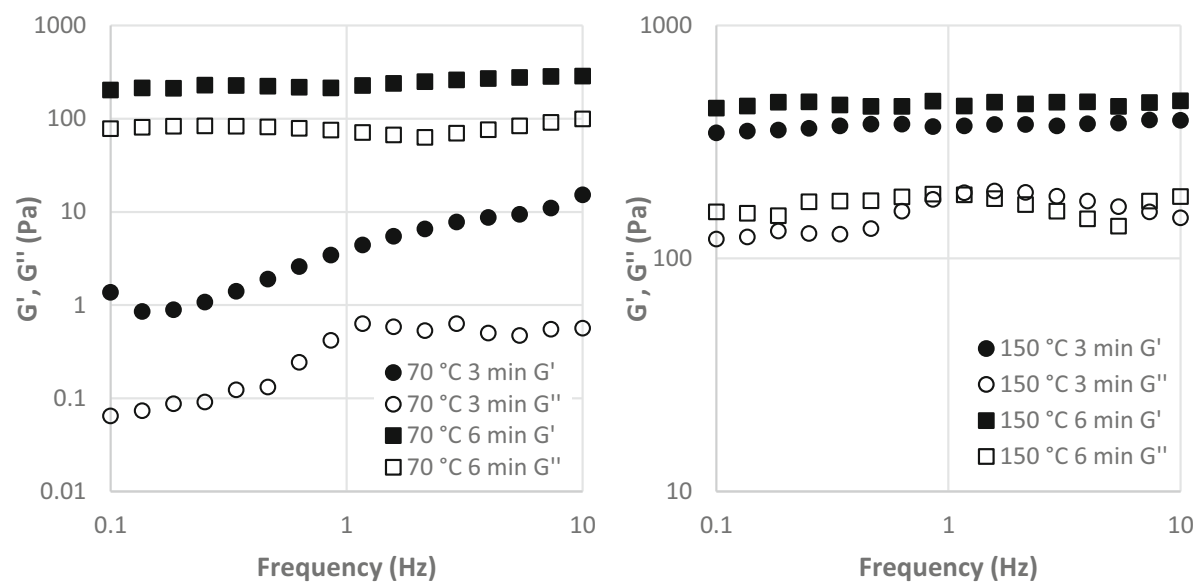

Fig. 7. Mechanical spectra (G': elastic modulus, G": viscous modulus) of representative hydrogels formulated with extracted hybrid carrageenan (1\%, w/w). Note here that the visualization scale of $y$-axis of both plots is different. Note here that in all cases deviations were lower than symbol sizes.

compounds than those reported for Mastocarpus stellatus and other similar red seaweeds using conventional techniques (sulfate, $0.6-3.9 \mathrm{~g} /$ $100 \mathrm{~g}$, protein, $0.1-3.4 \mathrm{~g} / 100 \mathrm{~g}, 4.9 \mu \mathrm{mol}$ Trolox equivalents/g) was also reported $[41,43]$.

Overall, the extracts obtained at $190{ }^{\circ} \mathrm{C}$ mainly contained $12 \%$ phenolics, $23 \%$ protein and $51 \%$ carbohydrates. Concerning the latter compounds, fundamental content for MAE soluble extracts treated at tested temperature and time conditions are summarized in Table 1. Again, no statistical impact of microwave heating time on carbohydrates compositions was found. However, a clear impact of microwave heating temperature was observed, with the highest carbohydrate content (around $66 \%$ ) at $170{ }^{\circ} \mathrm{C}$. The obtained carbohydrates are in well harmony with those previously reported for red seaweeds [44,45]. Glucose, xylose and galactose contents increased with rising heating 


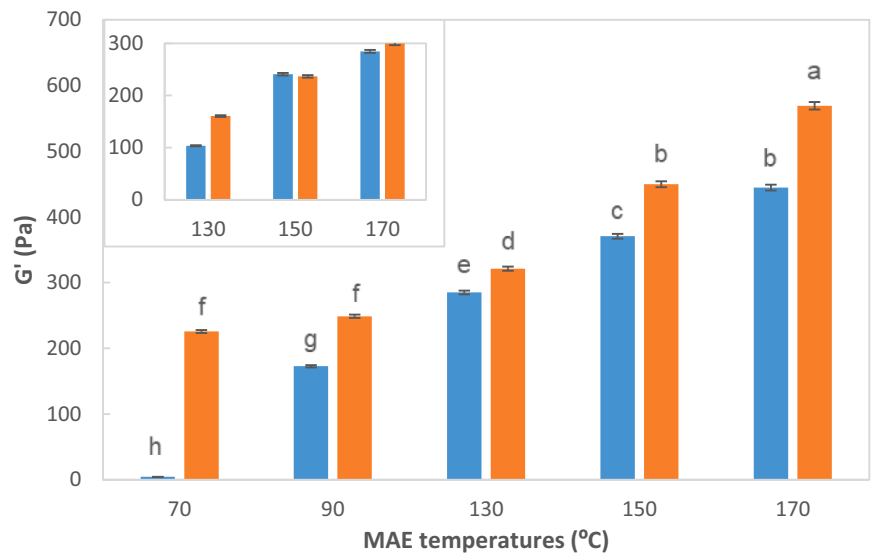

Fig. 8. Overview of the elastic modulus (G') at $1 \mathrm{~Hz}$ for all tested systems prepared at $1 \%$ of biopolymer content. Inset represents the effect microwave assisted extraction (MAE) temperatures (x-axis) in the elastic behavior at $1 \mathrm{~Hz}$ (y-axis) for gelled samples made at $0.5 \%$. Symbols: time of $3 \mathrm{~min}$ (blue bars), time of 6 min (orange bars). Data values were presented as average \pm standard deviations $(n=3)$. (For interpretation of the references to colour in this figure legend, the reader is referred to the web version of this article.)

temperature up to $170{ }^{\circ} \mathrm{C}$, whereas their content significantly dropped at the highest tested temperature, which suggests some polysaccharides degradation at the highest processing temperatures $[25,26]$. It should be highlighted that the carbohydrates recovered in soluble extracts treated at $170{ }^{\circ} \mathrm{C}$ are even higher than those obtained from other similar red seaweeds treated using enzyme- or ultrasound- assisted extraction methods [46]. Note here that acetic acid significantly decreased over the tested temperature range; whereas formic acid exhibited the reverse trend.

\subsection{Physical properties of the extracted biopolymers}

The hybrid carrageenan separated from the liquid extracts was also characterized. Fig. 4 presents the yield of the biopolymers obtained after microwave treatment of Mastocarpus stellatus red seaweed. The extraction time was influential at temperatures under $150{ }^{\circ} \mathrm{C}$, but less important at higher temperatures. This behavior can be related with the solubilization temperatures of hybrid carrageenans, which is around $90{ }^{\circ} \mathrm{C}$ for conventional extraction procedures [12]. Moreover, the extraction yield showed a maximum of $60 \%$ at $150{ }^{\circ} \mathrm{C}$, more than double the yield attained at $190{ }^{\circ} \mathrm{C}$. Even though, the hybrid carrageenan extraction yields were improved using microwave assisted extraction when compared with long optimized conventional procedures, except at the milder conditions $\left(70^{\circ} \mathrm{C}\right)$ where similar magnitudes were identified. Namely, yields from conventional carrageenan extraction treatments for these type of carragenophyte seaweeds are usually around $20 \%[9,10]$.

Fig. 5 shows the corresponding FTIR-ATR spectra of extracted hybrid carrageenans, mainly made for kappa and iota disaccharide units in the backbone. In general, data in plot shows that the extraction time did not notably influenced the FTIR-ATR profiles, although some attenuation in the intensities were observed at $190{ }^{\circ} \mathrm{C}$ for $3 \mathrm{~min}$ and $70-90{ }^{\circ} \mathrm{C}$ for $6 \mathrm{~min}$. In all cases, the characteristic iota (at $805 \mathrm{~cm}^{-1}$ ) and kappa (at $845 \mathrm{~cm}^{-1}$ ) bands corresponding to 3,6-anhydro-galactose-2-sulfate and galactose-4-sulfate, respectively, were clearly identified [40]. The existence of 3,6-anhydro-galactose was corroborated by a relatively strong IR absorption band at $930 \mathrm{~cm}^{-1}$. Extracted carrageenans also featured a wide band at $1240 \mathrm{~cm}^{-1}$ ascribed to the $\mathrm{S}=\mathrm{O}$ stretching vibration of the sulfated groups [37]. Consequently, the obtained FTIR profiles for Mastocarpus stellatus extracts are consistent with those described for kappa/iota-hybrid carrageenans from a number of red seaweeds $[12,34]$. In order to estimate the kappa/iota carrageenan hybridization, the intensity ratio of IR absorption bands at 805 and $845 \mathrm{~cm}^{-1}$ was calculated as previously described [41]. For all samples, the estimated ratios presented values between 0.29 and 0.35 , showing the prevalence of kappa against iota carrageenan nature. This behavior is consistent with the outcomes previously found for carrageenans from Mastocarpus stellatus using conventional alkali treatments with values of hybridization around $0.31[41,47]$.

The molecular weight distribution in the hybrid carrageenan extracted at 3 and 6 min is presented in Fig. 6 . No peaks in the studied interval were observed for the extracts obtained at $70{ }^{\circ} \mathrm{C}$. The extracts obtained at higher temperatures showed peaks under $1 \mathrm{kDa}$ and higher than $80 \mathrm{kDa}$. The extracts obtained after $3 \mathrm{~min}$ at 90 and at $130{ }^{\circ} \mathrm{C}$ showed two peaks higher than $80 \mathrm{kDa}$, but at higher temperatures or at 6 min heating time, only one peak was observed. The signals of these peaks increased with the extraction temperature and were maximal in the extracts obtained at 130 and $150{ }^{\circ} \mathrm{C}$ when the extraction time was $3 \mathrm{~min}$ and at $170{ }^{\circ} \mathrm{C}$ for the extracts produced after $6 \mathrm{~min}$. The intensity of the signals was three times higher for the extracts obtained at $6 \mathrm{~min}$. The molecular weights of extracted hybrid carrageenans are consistent with those previously reported for other edible carrageenophyte red seaweeds [12]. The average molecular weights of those hybrid carrageenans recovered at $170{ }^{\circ} \mathrm{C}$ for 6 min are comparable with equivalent commercial kappa and iota- carrageenans [13]. To sum up, the range of molecular weight distributions obtained in extracted hybrid carrageenans is a critically relevant feature in order to achieve biopolymers with a wide range of mechanical properties $[1,48]$.

\subsection{Mechanical characterization of formulated hybrid carrageenan hydrogels}

Fig. 7 shows the viscoelastic behavior at $25{ }^{\circ} \mathrm{C}$ of representative kappa/iota- hybrid carrageenans $(1 \%, w / \mathrm{w})$ prepared in $\mathrm{KCl}(0.1 \mathrm{~mol} /$ L). Most systems presented elastic and viscous moduli independent of frequency with the elastic modulus larger than the viscous one over the tested frequency, which is indicative of gel materials [48]. Note here that only very weak gel properties were identified for those systems formulated with hybrid carrageenans extracted at the milder microwave conditions $\left(70{ }^{\circ} \mathrm{C}\right.$ for $3 \mathrm{~min}$ ), which is consistent with the molecular weight distribution profiles aforementioned. Another developed hydrogels here featured intermediate strength according the elastic and viscous moduli values. Similar viscoelastic tendencies were observed for those systems formed at lower carrageenan content $(0.5 \%, w / \mathrm{w})$, although with lower values (around half) of both moduli and then weaker gelling characteristics. The achieved viscoelastic magnitudes are in the range of those previously reported for other hybrid carrageenans extracted using conventional procedures [12,47,49].

The impact of microwave heating temperature and time on mechanical properties of formulated hydrogels can be clearly observed in Fig. 8. In general, $G_{\text {gel }}^{\prime}(1 \mathrm{~Hz})$ increased with increasing microwave temperature and time up to $170{ }^{\circ} \mathrm{C}$, which involves the enhancement of the gel strength. A higher effect of both parameters was identified at higher biopolymer content. Note here that no gels were achieved with hybrid carrageenans at $190{ }^{\circ} \mathrm{C}$ independently of extraction time at selected ionic strengths, may be related with the small signals observed in HPSEC profiles. This suggests that higher biopolymer content or ionic strength should be tried to obtain hydrogels for this carrageenan [13]. Overall, analyzing jointly the carrageenan extraction performance and the mechanical properties of the corresponding hydrogels, it seems that hybrid carrageenans treated between 150 and $170{ }^{\circ} \mathrm{C}$ for 6 min presented the most adequate biopolymer features.

\section{Conclusions}

Microwave assisted water extraction of hybrid carrageenans, proteins, carbohydrates and antioxidant compounds from Mastocarpus stellatus red alga was tested using an environmentally friendly process 
with enhanced extraction yields. A noticeable effect of microwave temperature was observed on the recovered soluble extracts properties, achieving the maximum values of proteins at $150{ }^{\circ} \mathrm{C}$, of carbohydrates at $170{ }^{\circ} \mathrm{C}$ and of antioxidants at $190{ }^{\circ} \mathrm{C}$. Concerning the gelling biopolymer fractions, the most adequate microwave treatment to obtain the highest yields is $150{ }^{\circ} \mathrm{C}$ for $6 \mathrm{~min}$. This microwave heating temperature should be increased up to $170{ }^{\circ} \mathrm{C}$ whenever it is sought to promote the strength of the hydrogels. Hybrid carrageenan-based hydrogels with stable viscoelastic properties and intermediate strength can be developed with the proposed microwave processing conditions. Another important industrial benefit is the absence of syneresis of the above hydrogels. Overall, it should be noteworthy that this novel work provided a set of kappa/iota - hybrid carrageenans with potential applications in food and non-food sectors to develop functional hydrogels, resulting from algae processed to different microwave heating temperatures for times, without jeopardizing the mechanical characteristics of the corresponding hydrogels.

\section{CRediT authorship contribution statement}

All the authors have read, approved, and made substantial contributions to the manuscript. HD and MDT conceived the study, made the drafting of the manuscript and the critical revision. EP and MDT made the experimental tests.

\section{Declaration of competing interest}

The authors declare no conflict of interest.

\section{Acknowledgements}

Authors thank the financial support to the Ministry of Science, Innovation and Universities of Spain (RTI2018-096376-B-I00). Financial support from the Xunta de Galicia (Centro singular de investigación de Galicia accreditation 2019-2022) and the European Union (European Regional Development Fund - ERDF), is grate fully acknowledged (Ref. ED431G2019/06). M.D.T. thanks Spanish Ministry of Science, Innovation and Universities for her postdoctoral grant (IJCI2016-27535 and RYC2018-024454-I).

\section{Informed consent, human/animal rights}

No conflicts, informed consent, human or animal rights applicable.

\section{Declaration of authors}

All authors agree to authorship and submission of the manuscript for peer review.

\section{References}

[1] V.L. Campo, D.F. Kawano, D.B. da Silva, I. Carvalho, Carrageenans: biological properties, chemical modifications and structural analysis - a review, Carbohydr. Polym. 77 (2009) 167-180.

[2] M.D. Torres, S. Arufe, F. Chenlo, R. Moreira, Coeliacs cannot live by gluten-free bread alone - every once in awhile they need antioxidants, International Journal of Food Science and Technology 52 (1) (2017) 81-90.

[3] S.M. Adl, A.G. Simpson, C.E. Lane, J. Lukeš, D. Bass, S.S. Bowser, M.W. Brown, M. Dunthorn Burki, V. Hampl, A. Heiss, M. Hoppenrath, E. Lara, L. Le Gall, D.H. Lynn, H. McManus, E.A. Mitchell, S.E. Mozley-Stanridge, L.W. Parfrey, J. Pawlowski, S. Rueckert, L. Shadwick, C.L. Schoch, A. Smirnov, F.W. Spiegel, The revised classification of eukaryotes, J. Eukaryot. Microbiol. 59 (2012) 429-493.

[4] C. Dawes, Chapter 4 macroalgae systematics, in: J. Fleurence, I. Levine (Eds.), Seaweed in Health and Disease Prevention, Elsevier, 2016(eBook ISBN: 9780128027936).

[5] M.D. Torres, S. Kraan, H. Domínguez, Seaweed biorefinery, Rev. Environ. Sci. Bio. 18 (2019) 335-388.

[6] M.L. Wells, P. Potin, J.S. Craigie, J.A. Raven, S.S. Merchant, K.E. Helliwell, A.G. Smith, M.E. Camire, S.H. Brawley, Algae as nutritional and functional food sources: revisiting our understanding, J. Appl. Phycol. 29 (2017) 949-982.
[7] L. Pereira, F. van de Velde, Portuguese carrageenophytes: carrageenan composition and geographic distribution of eight species (Gigartinales, Rhodophyta), Carbohydr. Polym. 84 (2011) 614-623.

[8] M.D. Torres, F. Chenlo, R. Moreira, Rheology of $\kappa / 1$-hybrid carrageenan from Mastocarpus stellatus: critical parameters for the gel formation, Int. J. Biol. Macromol. 86 (2016) 418-424.

[9] H.J. Bixler, H. Porse, A decade of change in the seaweed hydrocolloids industry, J Appl. Phycol. 23 (2011) 321-335.

[10] R. Boulho, C. Marty, Y. Freile-Pelegrín, D. Robledo, N. Bourgougnon, G. Bedoux, Antiherpetic (HSV-1) activity of carrageenans from the red seaweed Solieria chordalis (Rhodophyta Gigartinales) extracted by microwave-assisted extraction (MAE), J. Appl. Phycol. 29 (2017) 219-228.

[11] R. Moreira, F. Chenlo, M.D. Torres, Gelling characteristics and rheology of kappa/ iota-hybrid carrageenans extracted from Mastocarpus stellatus dried at different temperatures, J. Appl. Phycol. 28 (2016) 3635-3644.

[12] G. Azevedo, M.D. Torres, I. Sousa-Pinto, L. Hilliou, Effect of pre-extraction alkali treatment on the chemical structure and gelling properties of extracted hybrid carrageenan from Chondrus crispus and Ahnfeltiopsis devoniensis, Food Hydrocoll. 50 (2015) 150-158.

[13] G. Azevedo, L. Hilliou, G. Bernardo, I. Sousa-Pinto, R.W. Adams, M. Nilsson, R.D. Villanueva, Tailoring kappa/iota-hybrid carrageenan from Mastocarpus stellatus with desired gel quality through pre-extraction alkali treatment, Food Hydrocoll. 31 (2013) 94-102.

[14] L. Pereira, F. Meireles, H.T. Abreu, P.J. Ribeiro-Claro, A comparative analysis of carrageenans produced by underutilized versus industrially utilized macroalgae (Gigartinales Rhodophyta), in: S.-K. Kim, K. Chojnacka (Eds.), Marine Algae Extracts Processes Products and Applications, Wiley-VCH Verlag GmbH \& Co KGaA, Weinheim, 2015, pp. 277-294.

[15] R. Moreira, F. Chenlo, M.D. Torres, C. Silva, D.M. Prieto, A.M.M. Sousa, L. Hilliou, M.P. Gonçalves, Drying kinetics of biofilms obtained from chestnut starch and carrageenan with and without glycerol, Dry. Technol. 29 (2011) 1058-1065.

[16] B. Domingues, M.H. Abreu, I. Sousa-Pinto, On the bioremediation efficiency of Mastocarpus stellatus (Stackhouse) Guiry, in an integrated multi-trophic aquaculture system, J. Appl. Phycol. 27 (2015) 1289-1295.

[17] H.P.S. Abdul Khalil, C.K. Saurabh, Y.Y. Tye, T.K. Lai, A.M. Easa, E. Rosamah, M.R.N. Fazita, M.I. Syakir, A.S. Adnan, H.M. Fizree, N.A.S. Aprilia, A. Banerjee, Seaweed based sustainable films and composites for food and pharmaceutical applications: a review, Renew. Sust. Energ. Rev. 77 (2017) 353-362.

[18] S. Arufe, M.D. Torres, F. Chenlo, R. Moreira, Air drying modelling of Mastocarpus stellatus seaweed a source of hybrid carrageenan, Heat Mass Trans 54 (2018) 177-184.

[19] L. Pereira, Seaweeds as source of bioactive substances and skin care therapy-cosmeceuticals, algotheraphy, and thalassotherapy, Cosmetics 5 (2018) 68.

[20] L. Pérez, E. Conde, H. Domínguez, Microwave hydrodiffusion and gravity processing of Sargassum muticum, Process Biochem. 49 (2014) 981-988.

[21] E. Vázquez-Delfín, D. Robledo, Y. Freile-Pelegrín, Microwave-assisted extraction of the carrageenan from Hypnea musciformis (Cystocloniaceae, Rhodophyta), J. Appl. Phycol. 26 (2014) 901-907.

[22] L. López-Hortas, H. Domínguez, M.D. Torres, Valorisation of edible brown seaweeds by the recovery of bioactive compounds from aqueous phase using MHG to develop innovative hydrogels, Process Biochem. 78 (2019) 100-107.

[23] N. Flórez-Fernández, M.P. Casas, M.J. González-Muñoz, H. Domínguez, Microwave hydrogravity pretreatment of Sargassum muticum before solvent extraction of antioxidant and antiobesity compounds, J. Chem. Tech. Biotech. 94 (2019) 256-264.

[24] M. Barral-Martínez, N. Flórez-Fernández, H. Domínguez, M.D. Torres, Tailoring hybrid carrageenans from Mastocarpus stellatus red seaweed using microwave hydrodiffusion and gravity, Carbohydr. Polym. (2020), https://doi.org/10.1016/j. carbpol.2020.116830.

[25] A.C. Soria, L. Ruiz-Aceituno, L. Ramos, L.M. Sanz, Microwave-assisted extraction of polysaccharide, in: K.G. Ramawat, J.M. Mérillon (Eds.), Polysaccharides, Springer International Publishing Switzerland, 2015.

[26] S.Ch. Wu, Antioxidant Activity of Sulfated Seaweeds Polysaccharides by Novel Assisted Extraction, (2017), https://doi.org/10.5772/intechopen.69633.

[27] D. Navarro, C. Stortz, Microwave-assisted alkaline modification of red seaweed galactans, Carbohyd. Polym. 62 (2005) 187-191.

[28] D. Navarro D, M. Flores, C. Stortz, Microwave-assisted desulfation of sulfated polysaccharides, Carbohyd. Polym., 69 (2007) 742-747.

[29] M. Magnusson, A.K.L. Yuen, R. Zhang, J.T. Wright, R.B. R.B. Taylor, T. Maschmeyer, R. de Nys, A comparative assessment of microwave assisted (MAE) and conventional solid-liquid (SLE) techniques for the extraction of phloroglucinol from seaweeds, Algal Res. 23 (2017) 28-36.

[30] S.E. Razzaghi, A. Arabhosseini, M. Turk, T. Soubrat, A. Cendres, M.H. Kianmehr, S. Perino, F. Chemat, Operational efficiencies of six microwave based extraction methods for orange peel oil, J. Food Eng. 241 (2019) 26-32.

[31] M. Llompart, C. Garcia-Jares, T. Dagnac, Microwave-assisted Extraction, Reference Module in Chemistry, Molecular Science and Chemical Engineering, (2019), pp. $67-77$.

[32] N. Flórez-Fernández, M.D. Torres, M.J. González-Muñoz, H. Domínguez, Recovery of bioactive and gelling extracts from edible brown seaweed Laminaria ochroleuca by non-isothermal autohydrolysis, Food Chem. 277 (2019) 353-361.

[33] V.L. Singleton, J.A. Rossi, Colorimetry of total phenolics with phosphomolybdic phosphotungstic acid reagents, American J. Enol. Viticult. 16 (1965) 144-158.

[34] R. Re, N. Pellegrini, A. Proteggente, A. Pannala, M. Yang, C. Rice-Evans, Antioxidant activity applying an improved ABTS radical cation decolorization assay, Free Radic. Biol. Med. 26 (1999) 1231-1237.

[35] M. Bradford, A rapid and sensitive method for the quantification of microgram 
quantities of protein utilizing the principle of protein-dye binding, Anal. Biochem. 72 (1976) 248-254.

[36] K.S. Dodgson, Determination of inorganic sulphate in studies on the enzymic and non-enzymic hydrolysis of carbohydrate and other sulphate esters, Biochem. J. 78 (1961) 312-319.

[37] L. Pereira, A.M. Amado, A.T. Critchley, F. van de Velde, P.J.A. Ribeiro-Claro, Identification of selected seaweed polysaccharides (phycocolloids) by vibrational spectroscopy (FTIR-ATR and FT-Raman), Food Hydrocoll. 23 (2009) 1903-1909.

[38] H.A. Ruiz, R.M. Rodríguez-Jasso, B.D. Fernandes, A.A. Vicente, J.A. Teixeira Hydrothermal processing, as an alternative for upgrading agriculture residues and marine biomass according to the biorefinery concept: a review, Renew. Sust. Energ. Rev. 21 (2013) 35-51.

[39] S.A.O. Santos, R. Félix, A.C.S. Pais, S.M. Rocha, A.J.D. Silvestre, The quest for phenolic compounds from macroalgae: a review of extraction and identification methodologies, Biomolecules, 9 (2019) art. no. 847.

[40] E. Gómez-Ordóñez, A. Jiménez-Escrig, P. Rupérez, Dietary fibre and physicochemical properties of several edible seaweeds from the northwestern Spanish coast, Food Res. Int. 43 (2010) 2289-2294.

[41] E. Gómez-Ordóñez, A. Jiménez-Escrig, P. Rupérez, Bioactivity of sulfates polysaccharides from the edible red seaweed Mastocarpus stellatus, Bioactive carbohydrates and dietary fibre 3 (2014) 29-40.

[42] J. Vega, F. Álvarez-Gómez, L. Güenaga, F.L. Figueroa, J.L. Gómez-Pinchetti, Antioxidant activity of extracts from marine macroalgae, wild-collected and cultivated, in an integrated multi-trophic aquaculture system, Aquaculture, 522 (2020) art. no. 735088 .

[43] M. Øverland, L.T. Mydland, A. Skrede, Marine macroalgae as sources of protein and bioactive compounds in feed for monogastric animals, J. Sci. Food Agr. 99 (2019) 13-24.

[44] J. Cotas, A. Leandro, D. Pacheco, A.M.M. Gonçalves, L. Pereira, A comprehensive review of the nutraceutical and therapeutic applications of red seaweeds (Rhodophyta), Life, 10 (2020) art. no. 19.

[45] D. Rodrigues, S. Sousa, A. Silva, M. Amorim, L. Pereira, T.A.P. Rocha-Santos, A.M.P. Gomes, A.C. Duarte, A.C. Freitas, Impact of enzyme-and ultrasound-assisted extraction methods on biological properties of red, brown, and green seaweeds from the central west coast of Portugal, J. Agri. Food Chem. 63 (2015) 3177-3188.

[46] A.D.P. Sánchez-Camargo, L. Montero, V. Stiger-Pouvreau, A. Tanniou, A. Cifuentes, M. Herrero, E. Ibáñez, Considerations on the use of enzyme-assisted extraction in combination with pressurized liquids to recover bioactive compounds from algae, Food Chem. 192 (2016) 67-74.

[47] L. Hilliou, Hybrid carrageenans: isolation, chemical structure and gel properties, Adv. Food Nutr. Res. 72 (2014) 17-43.

[48] L. Hilliou, F.D.S. Larotonda, P. Abreu, A.M. Ramos, A.M. Sereno, M.P. Gonçalves, Effect of extraction parameters on the chemical structure and gel properties of kappa/iota-hybrid carrageenans obtained from Mastocarpus stellatus, Biomol. Eng. 23 (2006) 201-208.

[49] L. Pereira, A.M. Amado, A.T. Critchley, F. van de Velde, P.J.A. Ribeiro-Claro, Identification of selected seaweed polysaccharides (phycocolloids) by vibrationa spectroscopy (FTIR-ATR and FT-Raman), Food Hydrocoll. 23 (2009) 1903-1909. 